\title{
IDENTIDADE OU ESTEREÓTIPO: A LEITURA HILSTIANA DO QUE É O BRASIL
}

Leandro Soares da Silva ${ }^{24}$

A prosa da "trilogia pornográfica" escrita por Hilda Hilst no início da década de 90 é, em parte, responsável pela sua fama de autora "erótica": fama esta apoiada por afirmações dela própria, que diversas vezes disse ter escrito tais livros com o único intuito de ganhar leitores. Durante muito tempo, os livros O caderno rosa de Lori Lamby, Cartas de um sedutor e Contos d'escárnio. Textos grotescos foram alvo das principais análises da obra de Hilst, em detrimento do resto de sua longa obra, algo que ela mesma já havia notado: "Esses estudos, essas teses, isso eu gosto quando fazem. Mas estão tratando principalmente das coisas eróticas. O meu teatro, por exemplo, ninguém faz" ${ }^{25}$.

Sobre o caráter "pornográfico" da prosa de Hilda Hilst muito já se escreveu, mas ainda não existe um consenso dos estudiosos sobre o assunto. Ao mesmo tempo em que não se pode negar a existência nesses livros de um conteúdo expresso de autêntica pornografia, não se pode deixar negar o tratamento de alto nível estético dado a ela, aliás, do mesmo tipo que se encontra nos demais trabalhos da autora. Não se pode confiar em sua assertiva de que os escreveu para poder alcançar o grande público (pois seus livros "sérios" exigem um leitor acostumado a procedimentos de vanguarda), uma vez que eles apresentam uma estrutura complexa que só um leitor experiente pode perceber, diferentemente do costumeiro apreciador de livrinhos eróticos vendidos nas bancas de jornal. Em resumo, a única diferença entre essa trilogia e os outros livros de Hilst é o conteúdo sexual expandido sem pudor de qualquer tipo, um afloramento de uma imaginação pornográfica ilimitada.

Uma das primeiras dissertações escritas sobre a "trilogia pornográfica", por exemplo, conclui que "as pretensões - sinceras ou não - da autora de fazer pornografia, rompendo com sua reconhecida produção anterior, de uma maneira ou de outra

\footnotetext{
${ }^{24}$ Mestre em Literatura e Diversidade Cultural pela Universidade Estadual de Feira de Santana. Professor Auxiliar de Literatura da Universidade do Estado da Bahia - Campus XX - Brumado.

${ }^{25}$ CADERNOS de Literatura do Instituto Moreira Salles Hilda Hilst, n. 8, out. 1999, p. 33.
} 
falharam" 26 . Este tipo de posicionamento leva em consideração uma classificação da literatura pornográfica como inferior ou funcionalmente orientada (para estímulo sexual e psicológico, por exemplo); considerando que o resultado final desses livros de Hilst, de fato, nem sempre apresenta características que poderiam ser imaginadas como pornográficas, muitos estudiosos têm preferido sustentar que não se trata de pornografia, mas de uma forma satírica adotada pela autora - que se serve do vulgar e do obsceno - e que raramente provoca no leitor excitação sexual.

Ainda há muito que se discutir sobre esses livros hilstianos. A nosso ver, contudo, trata-se de uma questão bizantina. Não é de muita importância classificar a escrita hilstiana de "pornográfica" ou "erótica", pois isso invariavelmente recai numa redução de um trabalho notável graças à sua complexidade. Por isso, neste ensaio não se propõe a busca de uma explicação para a presença dessas narrativas no corpus literário hilstiano, pois entendemos que elas representam uma etapa natural e até coerente na produção em prosa da autora. O que se propõe demonstrar é o uso que Hilst faz da pornografia, do erótico e do cômico para acusar uma identidade nacional estereotipada e mesmo nociva. Veremos que a escrita desses livros pode ser, na verdade, uma crítica radical a valores considerados típicos do brasileiro e, mais que isso, eles seriam um gesto de repúdio à canalhice e ignorância que imperariam no país.

Além dos livros já citados, também será incluído nesta análise o volume de crônicas reunidas, publicado no jornal Correio popular, de Campinas, entre julho de 1992 e julho de 1995, e posteriormente editadas sob o título Cascos \& carícias. A inclusão dessas crônicas se dá pelo fato de possuírem o mesmo espírito das narrativas da "trilogia pornográfica".

Em O caderno rosa de Lori Lamby, primeira das obras a ser publicada, lemos no diário homônimo de uma menina de oito anos suas aventuras sexuais, como prostituta, com homens mais velhos. Ao mesmo tempo, tomamos conhecimento dos problemas enfrentados por seu pai escritor quanto à criação e o mercado editorial. O livro se desdobra como um interessante jogo ficcional em que narradores e narrativas díspares apresentam-se e às vezes fundem-se. Na verdade, todos esses livros, com exceção das crônicas, foram escritos com a liberdade (e complexidade) típica do que se

${ }^{26}$ AZEVEDO FILHO, Deneval Siqueira de. Holocausto das fadas: a trilogia obscena e o carmelo bufólico de Hilda Hilst. São Paulo: Annablume/ Edufes, 2002, p. 92. 
convencionou chamar de prosa pós-moderna. Daí a irrupção repentina, dentro da narração, de trechos de cartas, referências e auto-referências, peças de teatro, contos e outros textos, num caleidoscópio de recursos que, aparentemente, têm pouca ligação entre si, mas que possuem uma função específica dentro de cada livro. Por este motivo, a descrição deles só pode oferecer uma visão geral e míope.

Algumas das características do romance pós-moderno mais presentes nesses livros é a anarquia de gêneros, que se realiza através da imitação de gêneros tradicionais, como, por exemplo, do romance libertino do século XVIII, do romance epistolar, da literatura destinada às crianças e da combinação inusitada no interior da narrativa com outras formas de escrita. Assim, por exemplo, em Lori Lamby, tendo por base um diário de menina, somam-se cartas, contos, fábulas, poemas eruditos, debates sobre literatura etc. como outras linhas narrativas

Outra característica da prosa pós-moderna que pode ser encontrada na "trilogia" (sobretudo no Caderno rosa de Lori Lamby) é a indefinição do narrador, que se divide em várias máscaras. Embora seja assumido, desde o início, o ponto de vista de um narrador, que é denominado seja pelo título (no caso de Lori), seja na própria narrativa, as vozes se misturam e não se torna tarefa fácil afirmar quem e de onde se narra. $\mathrm{O}$ caso de Lori Lamby é exemplar e curioso, pois explicá-lo significa destituir do leitor o sabor da surpresa que se anuncia ao final do livro.

Voltando às questões principais deste ensaio, o tempo todo, em Lori Lamby, Hilst metaforiza situações para usar em suas críticas. É assim, por exemplo, que se identifica o Brasil, por metonímia, com "bananeira", que, por sua vez, se transforma em "bandalheira":

O Lalau falou pro papi: por que você não começa a escrever umas bananeiras pra variar? Acho que não é bananeira, é bandalheira, agora eu sei.

"Isto sim é que é uma doce e terna e perversa bandalheira!" (desculpe, papi, bananeira. Eu sempre me atrapalho com essa palavra $)^{27}$.

A bananeira, representando um ícone de brasilidade (será necessário lembrar os cachos de banana no turbante de Carmem Miranda ou apelar para epítetos como

${ }^{27}$ HILST, Hilda. O caderno rosa de Lori Lambi. São Paulo: Globo, 2005, p. 19 e 94, respectivamente. 
"República das Bananas"?) é aproximada por paronomásia a "bandalheira", como se a nação estivesse conspurcada dentro de um elemento que lhe serve de referência. Além disso, neste livro, encontram-se alusões à sexualização precoce de meninas causada pela mídia (Lori sonha em adquirir produtos de "Xoxa", uma apresentadora infantil), ao mercado editorial brasileiro e às dificuldades (que a própria Hilst enfrentava) de ser lido e publicado neste país: "papi vai morar em Londres LONDRES! E aprender vinte anos o inglês e só escrever em inglês porque a fedida da puta da língua que ele escreve não pode ser lida porque são todos ANARFA [...]" 28 .

Nos Contos d'escárnio, além das experiências libidinosas de Crasso, o personagem-narrador, existe também uma crítica ao mercado editorial na figura da personagem que funciona como alter ego de Hilst, um escritor suicida que não apenas escreve no estilo hilstiano mais metafísico, como possui suas iniciais: Hans Haeckel. Ao longo do livro, abundam referências a um Brasil atrasado e arcaico, figurado em descrições de uma vida interiorana cercada de luxúria.

Destaca-se a paródia de Lisístrata, clássico do teatro cômico grego, que irrompe a narrativa. Hilst coloca em cena, sob o título de Teatrinho nota 0 , uma galeria de personagens femininas que, ao contrário do que acontece no texto parodiado, querem acabar com a guerra para fazer sexo. A realização estilística mostra o esmero da autora: toda escrita em versos, alternando entre palavras raras e eruditas com outras de baixíssimo calão, cheia de referências literárias que vão do teatro antigo à psicanálise de Freud, passando por Shakespeare e pelos hippies, sem soar esnobe ou hermético. É um texto no qual o obsceno convida ao riso e ao prazer. Em determinado momento, uma das personagens tem uma visão, enviada pelos deuses, de um país do futuro que "só vai ter picas bolas cachaças e cricas", onde irão "escorraçar os letrados e o monstro das letras" ${ }^{29}$. Não conformados, os deuses resolvem dar um retrato falado desse futuro país. A rubrica que lhe segue diz o seguinte:

Começa a descer do alto do palco uma grande roda de carroça igual a uma bandeja. Ao redor da roda, cacetas como luminárias. No centro da roda, garrafas de cachaça. E lindas mulatas. Sambando, naturalmente. [...] As mulatas descem da bandeja, invadem o palco aos gritos de "Viva o Brasil!" várias vezes. O

\footnotetext{
${ }^{28}$ Id., p. 85.

${ }^{29}$ HILST, H. Contos d'escárnio. Textos grotescos. São Paulo: Globo, 2002, p. 66.
} 
palco está em festa. Seleção de futebol, samba, música muito frenética $^{30}$.

Nessa aparição inusitada, que é um emblema bastante claro do projeto contestador da autora, pode-se perceber melhor a crítica que Hilst faz ao atraso cultural e educativo do país, simbolizado pela roda de carroça, à sexualidade desenfreada e aos símbolos nacionais como a cachaça, a mulata, o futebol e o samba. Ao atribuir a signos classicamente reconhecidos como brasileiros uma carga negativa, Hilst, além de fazer sua crítica, revela o estereótipo por trás deles. Também se deve notar a alusão ao "país do futuro", metonímia para o Brasil há muito tempo, desde que Stephen Zweig escreveu seu livro. A peça termina com uma canção final entoada por todos: "Temos tudo nas mãos/ Bolas cricas gingas e tretas!/ Temos a pica mais dura do planeta!/ Viva o Brasil!" 31.

Há aqui um abuso dos estereótipos nacionais concernentes a alguns de seus ícones, como a mulata, a cachaça ou o samba. O recado, de tão altissonante, pode soar ao leitor como preconceituoso: mas conotação negativa que Hilst atribui a esses "índices de brasilidade" faz parte de uma crítica ao que se considera, ao longo do livro, como atrasado, arcaico, subdesenvolvido - isto é, a valorização do sensual e do pitoresco, em detrimento de valores mais "cerebrais", como a introspecção da leitura, por exemplo.

Nas crônicas, Hilst fica mais livre para fazer suas críticas e explorar os estereótipos brasileiros. Mostra sua indignação com o momento político, em plena crise de escândalos de corrupção e impeachment. Usando o riso como forma de desarticulação para fornecer suas opiniões, Hilst, vez ou outra, rompe com os padrões usuais do modelo de crônica para criar efeitos, a nosso ver, muitos mais diretos.

No trecho a seguir, o homem brasileiro, no seu estereótipo de "macho" é ridicularizado e invertido: "seo Macho Silva, hôhô hôhô, enquanto fornicas bundeiramente as tuas mulheres cantando, chutando a bola, que pepinão, seo Silva, na tua rodela [...] grande pobre macho saqueado, de bruços, de joelhos, há quanto tempo cedendo e disfarçando, vítima verde-amarela $[\ldots]^{, 32}$. Em outro momento, ao falar do caso do presidente Itamar Franco, visto no sambódromo ao lado de uma mulher sem

\footnotetext{
${ }^{30}$ Id., p. $67-8$.

${ }^{31}$ Id., p. 68.

${ }^{32}$ HILST, H. Cascos \& carícias. São Paulo: Nankin Editorial, 1998, p. 24.
} 
calcinha, Hilst comenta: "Eu adoro o Brasil! É tão frondoso, barroco, imprevisível, louco, tão cafô, tão nada sério que todo mundo se sente esquizo [esquizofrênico], mas sem culpa, em ser brasileiro" 33 . Hilst usa esse episódio para lembrar como a recepção aos seus livros obscenos foi tão conservadora e cheia de pudicícia, sendo que, como ela nos lembra, este é um país que tem entre seus estandartes nacionais a mulata seminua e voluptuosa. Numa outra crônica, sobre a feira do livro em Frankfurt, Hilst sugere como seria o pavilhão dedicado ao Brasil:

Mandar índios empalhados, múmias de escritores, por exemplo, eu mesma [...]. Por que não mandam os dedinhos do PC Farias, aquilo roxo do Collor, a calcinha da outra, o topete do presidente, o orgasmo epiléptico da Daniela Mercury tal como uma enguia estertorando nas redes e entupida de Antártica? E os entulhos de Angra dos Reis, por que não? [...] Ô terra fofa a nossa! Ô país porreta o nosso! E livrinhos em tupi-guarani? E uma paisagem tranqüila de Quirinquinquá? "E porr que non aquelas cabecinhas de jagunças ton perrfeitamente rreduzidas? Lampion e Marria Bonito? Ton bonitinhos brrasileirrinhos, coitadas!"

E por que não pelo menos uma fotografia dos únicos escritores do mundo, os brasileiros, que em vida são definitivamente considerados mortos? ${ }^{34}$

Pode-se perceber, pelos exemplos, e na leitura das inúmeras crônicas, que o projeto de Hilst neste livro é ironizar o Brasil através de suas próprias contradições e dos símbolos identificados com o caráter nacional. A autora se utiliza de formas e signos comuns a todos (como as mulheres, a música, os índios, as belezas naturais etc.) para mostrar que, no Brasil, escrever obscenidades ou pornografia é coisa mais que banal. "Em terra de pornógrafos, para Hilda Hilst, o que cabe ao escritor sério é a revelação da pornocracia, isto é, da violência hegemônica da identidade bandalha" afirma Alcir Pécora na introdução a Contos d'escárnio. Antes, ele já havia escrito:

Outra relação [...] é a que existe entre seu relato obsceno e as circunstâncias do Brasil, que trata como país bandalho por antonomásia: terra desolada onde o poder injusto e ilegítimo pactua com a venalidade mais mesquinha por meio da celebração da malandragem e do triunfalismo carnavalizante. $\mathrm{Na}$ costumeira louvação da esperteza do jeitinho nacional, Hilda

${ }^{33}$ Id., p. 115.

${ }^{34}$ Id., p. 129. 
reconhece perfeitamente o selo da cumplicidade geral da bandidagem contra a esperança do conhecimento, de que a liberdade da literatura poderia ser a principal caução ${ }^{35}$.

A "trilogia pornográfica" se configura, deste modo, não como um truque para conseguir leitores ou criar polêmica, mas como uma atitude crítica radical contra os valores reconhecidos como brasileiros que, em certo sentido, oprimem o florescimento do conhecimento e das artes. Hilst acusa as identidades nacionais como aquilo que elas de fato são, "coisas com as quais nós nascemos, mas [que] são formadas e transformadas no interior da representação" ${ }^{36}$.

Por outro lado, os estereótipos acusados por Hilst, através de uma linguagem insolente e uma atitude agressiva, foram e são amplamente vendidos pelo governo, e se encontram, já há algum tempo, incorporados ao inconsciente coletivo brasileiro. Futebol, carnaval, cachaça e mulatas sensuais, só para ficar nesses exemplos, são mitos onipresentes no imaginário nacional, reiterados sempre que possível, seja na publicidade, na cultura popular ou no comportamento das pessoas.

Roberto DaMatta, no livro O que faz o brasil, Brasil?, se dedica justamente a uma investigação dessas características que todos atribuímos como tipicamente nacionais e constituintes de nosso caráter: culinária, carnaval, mulatas, malandragem e “jeitinho", entre outras. Suas observações são muito interessantes e válidas, mas neste livro não se encontra uma avaliação crítica que pese os fatores negativos dessa identidade. Hilda Hilst, pelo contrário, tenta denunciar exatamente esse tipo de celebração que, para ela, constitui um atestado de atraso. É como se a indignação da autora - lembremos: perpassada pela ironia e pelo deboche - se voltasse contra este tipo de estereótipo "positivo" que só ajuda a contribuir com o subdesenvolvimento, a corrupção e a ignorância do país: afinal, qual não tem sido a justificativa para frases sempre ouvidas como a de que "a corrupção brasileira é uma coisa cultural", e similares?

A título de exemplo, compare-se o que DaMatta tem a de dizer sobre malandragem e "jeitinho" com o que Pécora havia afirmado na citação da página anterior:

${ }^{35}$ Id., Ibid.

${ }^{36}$ HALL, Stuart. A identidade cultural na pós-modernidade. Rio de Janeiro: DP\&A, 2000, p.48. 
A malandragem não é simplesmente uma singularidade inconseqüente de todos nós, brasileiros. Ou uma revelação de cinismo e gosto pelo grosseiro e pelo desonesto. É muito mais que isso. De fato, trata-se mesmo de um modo - jeito ou estilo profundamente original e brasileiro de viver, e às vezes sobreviver [...]. Num mundo tão profundamente dividido, a malandragem e o "jeitinho" promovem uma esperança de tudo juntar numa totalidade harmoniosa e concreta. Essa é a sua importância, esse é o seu aceno. Aí está a sua razão de existir como valor social ${ }^{37}$.

As palavras de Edward Said resumem bastante bem o que se tentou dizer até aqui: "a preocupação ideológica com a identidade está compreensivelmente entrelaçada com os interesses e programas de vários grupos - nem todos minorias oprimidas - que desejam estabelecer prioridades que reflitam tais interesses" ${ }^{\text {} 38}$.

Seria importante buscar quais grupos teriam interesses - e por que - no caso brasileiro. A construção de uma identidade que se afirma através de estereótipos baseados em signos que denotam felicidade ou sociabilidade (carnaval, malandragem, futebol etc.) é difundida pelos meios de comunicação em massa e apoiada pelos órgãos oficiais do governo (e não somente as secretarias de turismo). Não existe, nessa celebração dos estereótipos nacionais, uma crítica dialética que leve em consideração os aspectos positivos (como o faz DaMatta), sem esquecer o reverso da moeda (como faz os textos hilstianos). Pois o estereótipo que tem nos servido para uma auto-celebração tem também sido usado como explicação para o estado geral das coisas - afinal, "isso é coisa de brasileiro" - e tal atitude se mostra de grande serventia para as classes dominantes que permanecem hegemônicas.

Renato Ortiz, por sua vez, afirma:

É através de uma relação política que se constitui assim a identidade; como construção de segunda ordem ela se estrutura no jogo da interação entre o nacional e o popular, tendo como suporte real a sociedade global como um todo. Na verdade a invariância da identidade coincide com a univocidade do discurso nacional. Isto equivale a dizer que a procura de uma "identidade brasileira" ou de uma "memória brasileira" que seja

\footnotetext{
${ }^{37}$ DAMATTA, Roberto. O que faz o brasil, Brasil? Rio de Janeiro: Rocco, 1986, 2a ed., p. 104-5.

${ }^{38}$ SAID, Edward W. Cultura e imperialismo. São Paulo: Companhia das Letras, 1995, p.27.
} 
em sua essência verdadeira é na realidade um falso problema. A questão que se coloca não é de se saber se a identidade ou a memória nacional apreendem ou não os "verdadeiros" valores brasileiros. A pergunta fundamental seria: quem é o artífice desta identidade e desta memória nacionais? [...] A idéia de construção nos remete a uma outra noção,a de mediação. [...] São os intelectuais que desempenham essa função de mediadores simbólicos. [...] A construção da identidade nacional necessita portanto desses mediadores que são os intelectuais ${ }^{39}$.

Sem dúvida, a crítica hilstiana também se dirige aos intelectuais, visto que muitos reprovaram seus textos "pornográficos", chegando ao ponto de, inclusive, desfazer laços de amizade que mantinham com ela. Isto também se torna patente quando se percebe, em todos esses textos, referências pejorativas ao que se convencionou chamar de "elite intelectual".

Mas, em suma, poderíamos dizer que o grande estereótipo brasileiro acusado nos livros é o da alegria. A literatura de Hilda Hilst, por outro lado, é "séria", invernal, toca em assuntos introspectivos demais e exigem uma reflexão interior; por isso, sua crítica a tais estereótipos da identidade brasileira significa a reação de alguém que não se sente contemplada esse estereótipo, mesmo porque sua literatura nunca deixou de representar, também, certa identidade nacional.

O cômico da trilogia pornográfica, expresso através da descrição vulgar e de um linguajar obsceno, serve como disfarce crítico ao que ele mesmo denuncia: fazendo-nos rir de nossas próprias construções discursivas acerca da nossa identidade, das "certezas" que nos anunciam como brasileiros e, ao mesmo tempo, nos limitam. Esses livros de Hilst, sob o signo da derrisão, são a outra face dos seus outros livros, consumidos por uma metafísica lúgubre, ainda que apaixonada.

De certa forma, o que seus textos propõem é uma atitude crítica em relação a esse "caráter brasileiro" que se identifica no jeitinho, no carnaval, no futebol e no samba. Ao mesmo tempo, revela que não somos tão liberados quanto esse "caráter" diz que somos, pois seus livros, usando o próprio discurso nacional da nossa identidade, são repudiados e criticados do modo mais conservador. O que nos lembra que este é um país das contradições. Se a mulata sambando seminua para o príncipe inglês é motivo de

\footnotetext{
${ }^{39}$ ORTIZ, Renato. Cultura brasileira \& identidade nacional. São Paulo: Brasiliense, 1994, pp. 139-40.
} 
orgulho para os brasileiros, uma velhinha denunciando a obscenidade da nação não pode ser.

\section{Referências:}

AZEVEDO FILHO, Deneval Siqueira de. Holocausto das fadas: a trilogia obscena e o carmelo bufólico de Hilda Hilst. São Paulo: Annablume/ Edufes, 2002.

CADERNOS de Literatura do Instituto Moreira Salles Hilda Hilst, n. 8, out. 1999.

DAMATTA, Roberto. O que faz o brasil, Brasil? 2a ed. Rio de Janeiro: Rocco, 1986.

HALL, Stuart. A identidade cultural na pós-modernidade. Rio de Janeiro: DP\&A, 2000.

HILST, Hilda. O caderno rosa de Lori Lambi. São Paulo: Globo, 2005.

. Cascos \& carícias. São Paulo: Nankin Editorial, 1998.

. Contos d'escárnio. Textos grotescos. São Paulo: Globo, 2002.

ORTIZ, Renato. Cultura brasileira \& identidade nacional. 5a ed. São Paulo: Brasiliense, 1994.

PÉCORA, Alcir. Nota do organizador. In: HILST, H. Contos d'escárnio. Textos grotescos. São Paulo: Globo, 2002.

SAID, Edward W. Cultura e imperialismo. São Paulo: Companhia das Letras, 1995. 